\title{
Cell-Free Biomimetic Mineralization Strategies to Regenerate the Enamel Microstructure
}

\author{
Yu Yuan Zhang ${ }^{1}$, Quan Li Li ${ }^{2}$ and Hai Ming Wong ${ }^{1, * \mathbb{D}}$ \\ 1 Faculty of Dentistry, The University of Hong Kong, 34 Hospital Road, Hong Kong SAR 999077, China; \\ u3004976@connect.hku.hk \\ 2 Collage and Hospital of Stomatology, Anhui Medical University, No. 69, Meishan Road, Heifei 230032, China; \\ ql-li@126.com \\ * Correspondence: Wonghmg@hku.hk; Tel.: +852-28590261
}

Citation: Zhang, Y.Y.; Li, Q.L.; Wong

H.M. Cell-Free Biomimetic

Mineralization Strategies to

Regenerate the Enamel

Microstructure. Crystals 2021, 11,

1385. https://doi.org/10.3390/

cryst11111385

Academic Editors: José L. Arias and Abel Moreno

Received: 12 October 2021

Accepted: 10 November 2021

Published: 12 November 2021

Publisher's Note: MDPI stays neutral with regard to jurisdictional claims in published maps and institutional affiliations.

Copyright: (c) 2021 by the authors. Licensee MDPI, Basel, Switzerland. This article is an open access article distributed under the terms and conditions of the Creative Commons Attribution (CC BY) license (https:// creativecommons.org/licenses/by/ $4.0 /)$.

\begin{abstract}
The distinct architecture of native enamel gives it its exquisite appearance and excellent intrinsic-extrinsic fracture toughening properties. However, damage to the enamel is irreversible. At present, the clinical treatment for enamel lesion is an invasive method; besides, its limitations, caused by the chemical and physical difference between restorative materials and dental hard tissue, makes the restorative effects far from ideal. With more investigations on the mechanism of amelogenesis, biomimetic mineralization techniques for enamel regeneration have been well developed, which hold great promise as a non-invasive strategy for enamel restoration. This review disclosed the chemical and physical mechanism of amelogenesis; meanwhile, it overviewed and summarized studies involving the regeneration of enamel microstructure in cell-free biomineralization approaches, which could bring new prospects for resolving the challenges in enamel regeneration.
\end{abstract}

Keywords: enamel-inspired mineralization; enamel-like structure; biomineralization; biomimetic mineralization

\section{Introduction}

Dental hard tissue is comprised of enamel, dentine and cementum. The bulk of the dental hard tissue is dentin, which covers the dental soft tissue (dental pulp) lying at the core of the tooth. Enamel is the outer layer that covers the dentine in the crown area and cementum is the outer layer, covering the dentine in the root area [1]. Compositionally, dentine (72\% inorganics, $20 \%$ organics and $8 \%$ water) and cementum $(45-50 \%$ inorganics, $50-55 \%$ organics and water) are the hydrated tissue [2,3]. Enamel is the hardest and most highly mineralized hard tissue in the human body, consisting of approximately $96 \%$ substituted hydroxyapatite (HA) and $4 \%$ water and organics [4]. As it is directly exposed to the oral environment, enamel is easier to be damaged. The acidic milieu generated by bacteria, acidic foods and beverages results in dental problems for 4 out of 5 deciduous teeth in children and over half of permanent teeth in adults [5]. Enamel is classified as acellular tissue. It cannot self-absorb or remodel; therefore, the damage is irreversible [6]. Generally, dental tissue defects are restored by artificial materials at the dental clinic. These traditional approaches are not ideal given the differences in chemical composition and physical properties between dental restorative materials and dental tissue. The incompatibility results in potential percolation (marginal microleakage) at the interface and causes a multitude of complications after dental restoration, such as secondary dental caries and dentine hypersensitivity.

Remineralization of the superficial dental tissue is a widely used, non-invasive therapeutic technique. Supersaturated solutions of calcium and phosphate, such as casein phosphopeptide-amorphous calcium phosphate (CPP-ACP), or fluoride varnish/gels are common agents for remineralization in clinical dentistry $[7,8]$. These agents promote enamel remineralization and are protective against dental caries; unfortunately, they do 
not integrate into the enamel microstructure and are unable to fully restore dental enamel. As such, in its current form, remineralization methods require several improvements to meet clinical demands. Thus, novel solutions for improving remineralization methods in clinical dentistry warrant further investigation.

The excellent biomechanical properties of enamel are attributed to its hierarchically organized structure at multiple levels (Figure 1). This hierarchical structure is composed of repeating units of tightly packed prisms (Figure 1B,C). Each prism is $4-8 \mu \mathrm{m}$ in diameter and composed of HA crystals bundled in parallel with one another. The cross-section of each crystal is $25-100 \mathrm{~nm}$ and an undetermined length of $100 \mathrm{~nm}$ to $100 \mu \mathrm{m}$ or larger along the c-axis (Figure 1C) [9]. Studies have shown that artificial materials with enamel-like structures have better biocompatibility than those with randomly oriented structures $[10,11]$. Thus, reproducing the unique dental prism structure of enamel is key in developing effective remineralization methods for treating dental lesions.

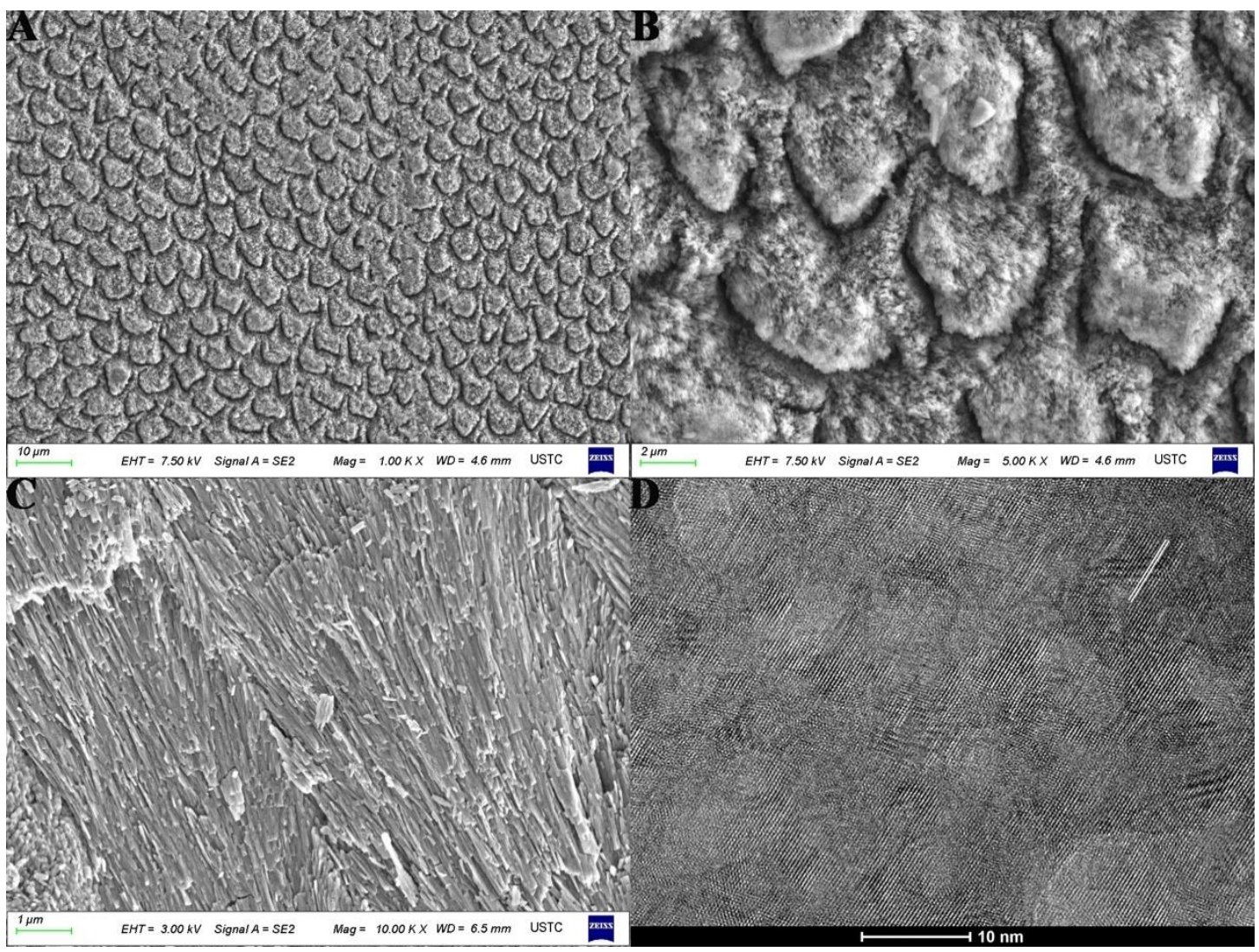

Figure 1. Scanning electron microscope (SEM) micrograph of acid-etched enamel shows highly ordered nano-HA crystallites assembled into enamel prisms (A-C). (A) Enamel prisms; (B) the magnified graph of (A); (C) parallelly oriented crystals assembling into prisms; (D) the high-resolution transmission electron micrograph (HRTEM) of enamel crystals $(\mathrm{d}$-spacing $=0.093 \mathrm{~nm})$.

In the past decades, researchers have been trying to regenerate the enamel-like structure using conventional synthetic approaches [9,12]. These methods utilized specialized conditions such as high temperature, high pressure or extreme acidic $\mathrm{pH}$. Some examples of such work include calcium phosphate paste containing hydrogen peroxide [12], a hydrothermal method with controlled release of calcium from Ca-EDTA [9], the hydrothermal transformation of octacalcium phosphate (OCP) rods into hydroxyapatite nanorods in the presence of gelatin $[13,14]$ and electrolytic deposition at $85^{\circ} \mathrm{C}[15,16]$. Unfortunately, all these methods are considered impractical at scale and cannot be translated to the clinic setting. 
Interdisciplinary work has provided a new framework for generating enamel-like structures. Inspired by the biomineralization process occurring in native organisms, scientists in the field of material chemistry have adopted ideas from nature to synthesize biomaterials with desirable structures [17]. Biomineralization in organisms involves a complex inorganic precipitation process which is precisely regulated by organic matrices (consisting mainly of proteins). During the biomineralization process, organic matrices are used as a template to control biomineralization. These matrices mediate nucleation and growth of inorganic crystal structures, resulting in various morphologies, sizes, orientations, and assemblies.

Based on the understanding of these mechanisms in native organisms, biomimetic mineralization strategies are currently under investigation for their application in medical engineering; in particular, biomimetic synthesis of repairing layers under physiological conditions $[18,19]$.

Current investigations into the mechanisms of amelogenesis have uncovered a diverse range of novel biomimetic strategies which the aim of reconstructing subsurface enamel lesions using remineralization processes. These strategies include positive ion selective membrane [20], direct calcium phosphate solution/paste mineralization [11,21,22], electrolytic precipitation [23], protein/peptide-induced mineralization [24-28] and nonprotein-induced mineralization [29-33]. All biomimetic strategies utilize an organic matrices template to control the nucleation, growth and features of HA crystals in order to regenerate enamel-like structures.

Insights regarding the molecular, physical and chemical mechanisms of amelogenesis in forming the hierarchically organized structure are indispensable to strategies in enamel regeneration. Here, we overview recent studies involving the regeneration of enamel microstructure in vitro, utilizing an organic matrices template, under relatively mild conditions, using a cell-free approach. Firstly, the general molecular mechanism of enamel formation from the view of physics and chemistry will be illuminated. The biomimetic methods regarding the development regeneration of enamel microstructure will then be presented. Lastly, we will provide an outlook for assessing future biomimetic mineralization strategies for enamel regeneration.

\section{Learning from Enamel}

\subsection{The Structure of Enamel and Its Mechanical Properties}

The highly oriented microstructure of enamel consists of crystals arranged in prisms or rods which run perpendicular from the dentine-enamel junction towards the tooth surface. This configuration leads to anisotropy of mechanical properties; thus, enamel represents the hardest tissue in the human body. The distinct mechanical properties of enamel have been characterized using different approaches [34]. The Young's moduli of enamel measured are in the range of 85-90 GPa parallel and 70-77 GPa perpendicular to the crystal rod axis; the mean hardness $4.79 \mathrm{GPa}$ parallel and $3.8 \mathrm{GPa}$ perpendicular to the enamel rods; and toughness approximately $0.7 \pm 0.02 \mathrm{MPa}^{*} \mathrm{~m}^{1 / 2}[35]$.

\subsection{The Process of Amelogenesis}

Enamel formation initiates at the dentino-enamel junction (DEI) and undergoes the following stages: organic matrix secretion, crystal nucleation, crystal elongation and enamel protein removal. During the secretory stage, ameloblasts differentiate into tall secretory cells which track along a cellular extension called Tomes' processes in order to secrete enamel matrix. The extracellular matrix contains enamel matrix proteins and proteinases [4].

\subsubsection{The Functional Role of Enamel Protein Matrices}

Enamel matrix protein is divided into amelogenin protein and hydrophilic nonamelogenin protein (e.g., ameloblastin, enamelin and tuftelin) [6]. 
The Function of Amelogenin Protein

Amelogenin is the major constituent of enamel protein, representing approximately $90 \%$ of the organic matrix within developing enamel. Amelogenin is secreted by ameloblasts and cleaved by proteinases [36]. Due to its amphiphilic properties, amelogenin selfassembles into a supramolecular scaffold, inducing and controlling the growth of enamel crystallization. The molecular structure of amelogenin consists of a hydrophobic tyrosinerich N-terminal domain (TRAP), a hydrophobic centralized proline-rich region and a charged C-terminal hydrophilic telopeptide ( $C$ telopeptide) [36]. TRAP and C telopeptide are the essential domains that regulate the hierarchical structure formation of enamel [37]. The TRAP domain predominately mediates the conformational transformation and selfassembly of amelogenin through protein-protein interactions [36]. C telopeptide binds with the apatite surface, which contributes to crystal growth and morphology. C telopeptide has a higher binding affinity to minerals (100) than to cross-sectional (001) faces, leading to the formation of enamel crystals with elongation along the c-axis [37].

Amelogenin is an intrinsically disordered protein containing abundant fractions of random coil structures ( $\beta$-turns and PPII-helices) and trace amounts of regular secondary structures ( $\beta$-sheets and $\alpha$-helices) [38]. After protein secretion and corresponding change in $\mathrm{pH}$, disordered amelogenin proteins transition to a folded state, leading to a higher ratio of $\beta$-sheet structures to random coils. At $\mathrm{pH} 3.5$, positively charged amelogenin molecules assemble into a monomeric structure by electrostatic forces. As $\mathrm{pH}$ increases, histidine residues of amelogenin deprotonate. At $\mathrm{pH}$ 5.5, N-terminal protein-protein interaction causes the aggregation of amelogenin monomers and its assembly into positively-charged oligomers (eight monomers). At $\mathrm{pH} \mathrm{8,} \mathrm{histidine} \mathrm{residuals} \mathrm{are} \mathrm{deprotonated,} \mathrm{leading} \mathrm{to}$ the termination of electrostatic forces and the predomination of hydrophobic forces. The transition of forces causes amelogenin oligomers to bind and gather into nanospheres with diameters ranging from 15 to $20 \mathrm{~nm}$ [39].

Amelogenin is the supramolecular template regulating enamel crystal growth, controlling enamel thickness and inducing elongated crystal formation $[38,40,41]$; however, the mechanisms underlying amelogenin-mineral interactions during amelogenesis remain unresolved. A classical and non-classical theory for amelogenin-mediated crystallization have been proposed.

Under the classical theory, amelogenin nanospheres serve as the main functional units in amelogenin-mediated crystallization. Amelogenin nanospheres bind to transient mineral surfaces (bonding affinity: (010) faces > (001) faces > (100) faces) to inhibit deposition and transform transient minerals into a highly-organized prism [42].

In the maturation stage of amelogenesis, mildly acidic environments and the positively charged surface of apatites promote histidine protonation and amelogenin nanosphere disassociation, resulting in the assembly of amelogenin nanospheres into an oligomeric structure [40]. The non-classical theory theorizes that the amelogenin oligomer plays a dominant role in crystal regulation during amelogenesis. The amelogenin oligomer is composed of a hydrophobic core and hydrophilic C-terminal tails surrounding its surface. Electrostatic interaction between charged $C$ telopeptides and the specific surface of mineral prenucleation clusters induces the envelopment of transient mineral phases by amelogenin oligomers, leading to formation of Amel-CaP nanoclusters. In Amel-CaP nanoclusters, mineral prenucleation clusters are stabilized within the double-barrel structured amelogenin oligomers. Those nanoclusters aggregate and self-assemble into linear chains in parallel arrays, dominating the formation of a prism-like structure (Figure 2) [43]. 


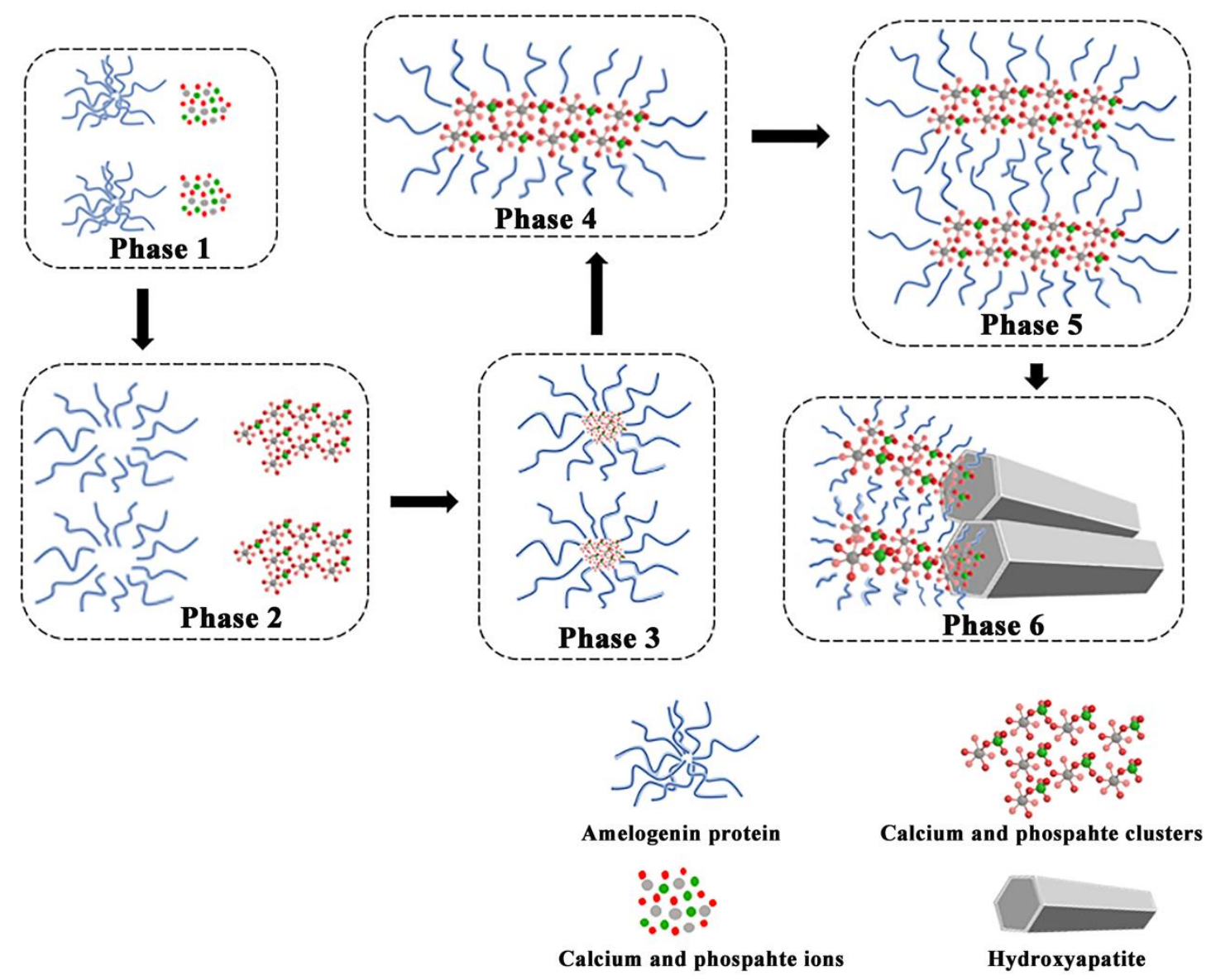

Figure 2. Mechanism of the amelogenin mediated biomineralization from prenucleation clusters into organized structure. Phase 1: the full-length amelogenin monomers and mineral ions; Phase 2: amelogenin oligomers and mineral prenucleation clusters; Phase 3: Amelogenin-CaP composites; Phase 4: Amelogenin-CaP nanoclusters assembled into linear chains; Phase 5: linear chains parallelly organized; Phase 6: the formation of elongated crystallites.

\section{The Function of Non-Amelogenin Protein}

Ameloblastin is the second most abundant matrix protein in enamel. Secreted in conjunction with amelogenin, the synergistic functions between these proteins play an important role in amelogenesis [37]. The synergistic functions between ameloblastin and amelogenin also play an important role in amelogenesis. Ameloblastin initiates crystal formation by its $\mathrm{C}$-terminals which have high-affinity towards calcium ions, thereby promoting calcium phosphate deposition; meanwhile, it induces the formation of prismatic structures by regulating the assembly of amelogenin molecules into an organized structure [44].

Enamelin is the least abundant protein among enamel protein matrices but is indispensable for an intact enamel layer formation. Enamelin regulates the conformational transformation and assembly of unfolded amelogenin molecules during amelogenesis via interactions between glycosylated sites of enamelin and the tyrosyl-rich $\mathrm{N}$-terminal region of amelogenin [45]. Enamelin also coordinates with amelogenin to induce calcium phosphate nucleation, enhance the stability of transient calcium phosphate minerals, increase crystal length-to-width ratio and results in the formation of elongated enamel crystals [45]. The combination of enamelin and amelogenin is protective against enamelin self-aggregation and inhibits aggregation of proteolytic products.

Tuftelin is an acidic phosphorylated glycoprotein [46]. It is synthesized by the ameloblast in the very early stages of enamel development and persists in extracellular enamel throughout development and mineralization, concentrating at the dentino-enamel 
junction region, where enamel mineralization commences. Tuftelin protein is implicated in caries susceptibility [47].

\subsubsection{The Functional Role of Proteinases}

Proteinases regulate the assembly of enamel matrix proteins, decrease protein-apatite binding affinity, inhibit protein occlusion within formed enamel crystals and contribute to the high degree of crystallization [48]. Metalloproteinase-20 (MMP-20) and serine protein kallikrein-4 (KLK-4) represent the two major enamel proteinases.

Secreted prior to the onset of dentine mineralization, MMP-20 is an enamel matrixprocessing enzyme that is activated during the enamel organics secretory stage and early enamel crystal maturation stage [49]. MMP-20 reacts with amelogenin during amelogenesis to produce proteolytic cleavage products [50]. These hydrophobic, proteolytic cleavage products incorporate with the remaining amelogenin molecules to form amphiprotic nanospheres with an isotropic distribution of C-terminals surrounding their surfaces. As proteolytic cleavage products increase, disassembled amphiprotic nanospheres rearrange into cylinder structures with a uniform hydrophilic molecular tail. The hydrophobic crosssection at the ends of cylindrical molecules interacts with other cylindrical molecules, resulting in the assembly of elongated chain-like structures. The hydrophilic tail creates repulsive forces between cylindrical molecules that inhibit bonding with one another. Once all amelogenins are digested by Mmp-20, the assemblies completely lose their hydrophilic surface layer of C-terminals, leading to neighboring cylindrical clusters stacking together and expanding the formation of larger units [50]. MMP-20 can also initiate the minerals transforming into crystallized hydroxyapatites [51].

KLK-4 is expressed in the transition and maturation stage of enamel crystals. The primary function of KLK-4 is to further promote the enamel crystallization and strengthen crystal hardness by digesting the proteolytic products of amelogenin, ameloblastic and enamelin cleaved by Mmp-20 [52]. In the absence of KLK-4, dental enamel has normal thickness and a prismatic structure, but severe defects in hardness and mineral crystallization.

The continuous secretion of enamel proteins and proteinases initiate mineral nucleation and rapid growth of enamel crystals towards the Tomes' process of ameloblasts at the DEJ. Mediation from enamel protein matrices provides a dominant position for growth on the crystal (001) plane, leads to the extension of the crystal c-axis, and results in increases in crystal length. Once the full extension of enamel crystals is finished, ameloblasts transform into a shortened height and lose their Tomes' process, resulting in the dramatic reduction of their secretory activity.

\section{Organic Matrices Mediated Mineralization}

\subsection{The Mechanism of Organic Matrices Mediated Mineralization}

Aggregation-based crystal growth is an important pathway for biomineralization, which results from the aggregation and coalescence of nanoparticles [53]. This pathway occurs through oriented or nearly-oriented attachment coexisting with random attachment induced aggregation-based growth and followed by stress-induced crystallization. Oriented and random attachment have been observed in the course of crystal growth [40-54]. Recent work showed the production of oriented attachment derived from the non-oriented growth front in the aggregation-based growth [55].

The oriented attachment strategy is an effective method for producing novel materials with collective properties and desired structure [56]. In naturally formed HA crystallites, organic matrices are used as a template to mediate the crystallization process and generate oriented attachment and highly organized structure. By using additives, the growth process of oriented attachment can be controlled in a manner that produces synthesized HA crystallites [56]. Native enamel is well-organized from the molecular to the nano-, micro- and macroscales and contains highly intricate nano-architectures. The functional, dynamic and hierarchical structures are built by a series of processes of enamel organic matrices self-assembly following a template. Organic matrix-mediated biomineralization 
is a mesoscale assembly occurring under mild physiological conditions, resulting in single crystals with oriented mosaic structures [57]. Organic matrices can control the structure and composition of crystal nuclei and modify the interactions of crystal nuclei to regulate particle size, texture, habit, aggregation and stability of intermediate phases. Through interfacial recognition, organic matrices also decrease the nucleation activation energy of specific crystal faces and polymorphs [58].

In using an organic matrix-mediated mineralization approach, a structural and geometric match between lattice spacings exists in certain crystal faces and the distances that separate functional groups. These are periodically arranged across an organic surface and are associated with a macromolecular matrix, which involves the role of molecular interactions in controlling oriented nucleation at the matrix-mineral interface [57]. Organic matrix-mediated mineralization is divided into classical and extended models. In the classical model, two different mineralization pathways have been suggested [58]. One pathway involves the binding of aqueous cations to functional sites of a macromolecular matrix to form a two-dimensional array. Subsequently electrical attraction of counteranions, which can decrease the activation energy for a specific crystallographic face, leading to the formation of oriented nucleation (Figure 3I). In the other pathway, mineral precursors are formed either directly from solution or by phase transformation of amorphous clusters in solution. Mineral precursors interact with organic matrix functional groups in a preferred crystallographic orientation (Figure 3II). In the alternative pathway, the resultant amorphous clusters are stabilized by macromolecules, bind to the organic matrix surface and undergo matrix-mediated mesophase transformations to form highly oriented crystals.

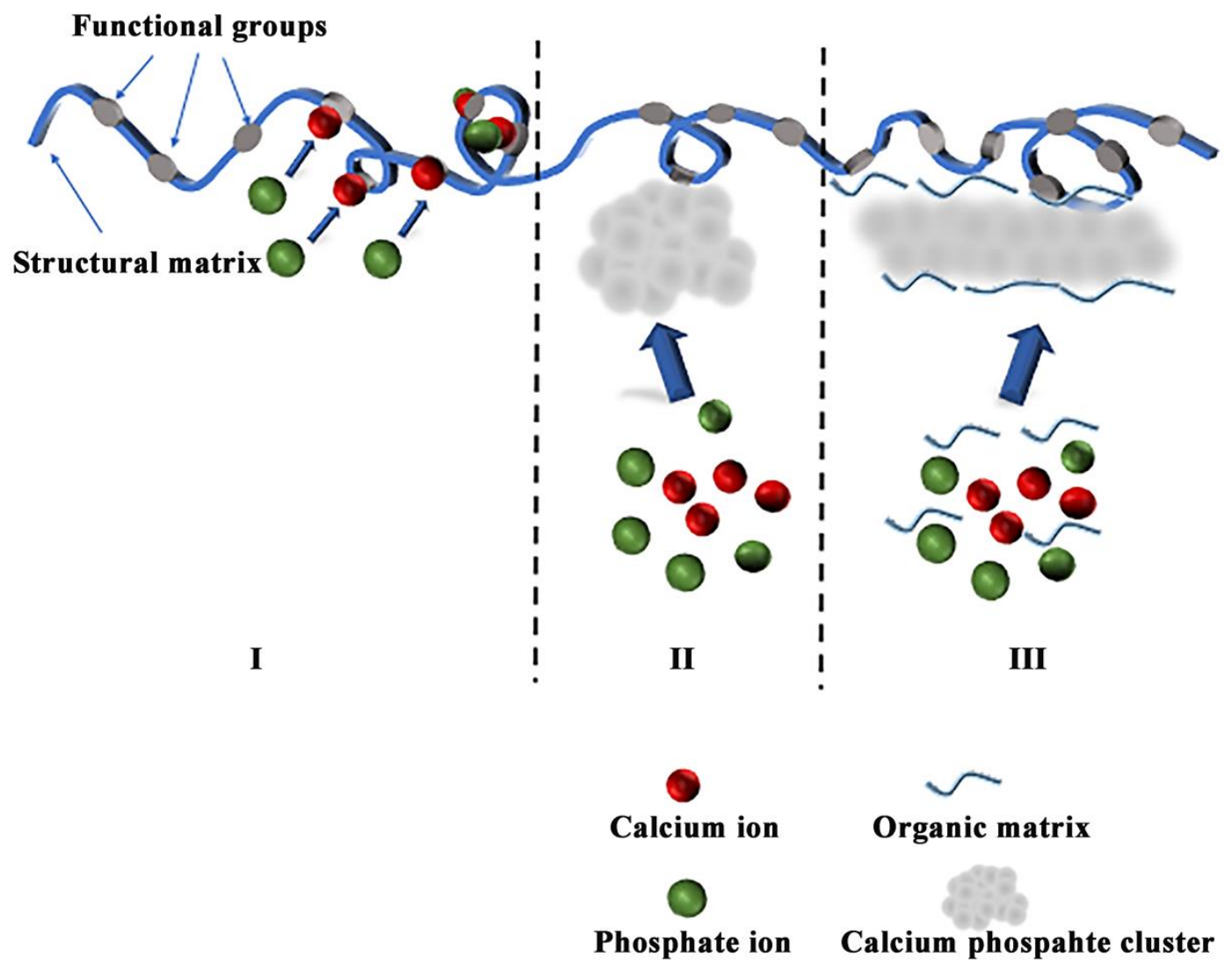

Figure 3. Classical and non-classical model in biomineralization (I,II), and extended models of organic matrix mediated mesoscale transformation to form highly oriented crystals (III).

In the extended model, crystal nucleation and the initial stages of growth occur within an interfacial layer [57]. Organic matrices (such as polymers and biomolecules) bind to amorphous clusters to produce textured hybrids, after undergoing controlled mesoscale 
assembly in aqueous solutions, through steric, van der Waals and hydrophilic-hydrophobic interactions. Formed hybrids consisting of inorganic cores and organic shells can be anchored by connectors to structural components of the organic matrix, which guide oriented attachment (Figure 3III).

In the organic matrix-mediated biomineralization system, organic matrices play the dominant role in formation of oriented attachment. Here, we overview the organic matrixmediated biomineralization systems applied in inducing the formation of enamel-like structure. In this review, the organic matrix-mediated mineralization system is presented and classified into protein and non-protein based organic matrix-mediated mineralization systems, based on the nature of organic matrices.

\subsection{Protein Based Organic Matrix-Mediated Mineralization System}

\subsubsection{Recombinant Amelogenin}

Amelogenin is the main organic protein in the extracellular matrix of enamel. Amelogenin controls mineral nucleation and regulates crystal growth and orientation. The degradation of amelogenin is induced by proteinases after completion of the full extension of enamel crystals [36]. Due to the difficulty and high cost regarding the extraction of native amelogenin, recombinant porcine/bovine amelogenin have been synthesized and applied directly to the enamel surface in order to recreate the distinct hierarchical structure. Recombinant amelogenin absorbs onto the side-facing mineral surfaces and stabilizes mineral precursors, suppresses its growth and controls the crystallization process [24,25]. Previous evidence showed that recombinant amelogenin has stronger binding affinities to mineral (010) faces than to (100) faces. Its addition results in crystal formation with small width to thickness and large length to width ratios [59]. It also leads to the formation of elongated ribbon-like crystals aggregated in parallel into a prismatic-like structure.

The functioning of recombinant amelogenin is enhanced by incorporating mineralization inhibitors (such as inorganic pyrophosphate or matrix metalloproteinase). These mineral inhibitors improve the regulation of crystal size, shape and orientation. They also prevent undesirable protein occlusion within newly formed crystals [24].

\subsubsection{Leucine-Rich Amelogenin Peptide (LRAP)}

The $\mathrm{N}$ - and C-terminals in full-length amelogenin serve as primary functional domains and are responsible for the formation of intact enamel [36]. LRAP is composed of $\mathrm{N}$ terminal (including the phosphorylation site) and C-terminal (including the hydrophilic domain) sequences of full-length amelogenin amino acids. LRAP is the smallest splice variant of full-length porcine amelogenin and shares similar properties with full-length amelogenin, such as mediating oriented attachment [26]. At pH 7 and $37^{\circ} \mathrm{C}$, LRAP nanospheres stabilize amorphous calcium phosphate and induce the formation of needlelike crystals with parallel orientation into an assemblage of chain-like structures [27].

\subsubsection{Human Dentine Phosphoprotein (DPP)}

A constituent of the extracellular matrix of dentine, DPP captures free $\mathrm{Ca}^{2+}$ and $\mathrm{PO}_{4}{ }^{3-}$ ions. DPP is involved in mineralization of the entire dentine layer and in bone calcification [60]. DPP contains numerous, repetitive aspartate-serine-serine (DSS) nucleotide sequences that function in inhibiting calcium phosphate dissolution and controlling crystal growth during dentine mineralization [29]. DSS is a highly flexible and phosphorylated sequence responsible for regulating crystal nucleation, growth and orientation [61]. Based on its properties, recent advancements have been developed for DSS-containing peptides in order to regulate the crystallization process and induce oriented attachment. Investigators in an in vitro study showed that DSS-containing peptides aided in the formation of a newly synthesized crystal layer with uniform structure and favorable mechanical properties, characteristics resembling native enamel [61]. 


\subsection{Non-Protein Based Organic Matrix-Mediated Mineralization System}

Several studies have explored the potential of a self-assembled protein-mediated biomineralization system, characterizing its functional roles in crystallization, induction of oriented attachment and regeneration of the native enamel's distinct hierarchical structure. The potential of this system is hindered by several limitations that limit its use in the clinical setting. As currently constructed, production of an appropriate crystal layer to restore enamel is considerably time-consuming. Moreover, methods need to be developed to overcome the present barriers in extraction, purification and storage of native proteins. Therefore, the non-protein mediated biomineralization system has been proposed and investigated.

\subsubsection{Self-Assembled Peptide}

Self-assembled peptides are widely used as a supramolecular template to synthesize nanostructured materials. The peptides spontaneously transition from a hierarchical self-assembly into a fibrillar scaffold. Driven by intermolecular hydrogen bonding, the process arises from the peptide backbone and additional interactions between specific sidechains [62].

Li et al. developed a novel, self-assembled peptide by covalently conjugating hydrophobic alkyl segments to oligopeptide segments derived from the hydrophilic Cterminal amino residues of amelogenin (-Thr-Lys-Arg-Glu-Glu-Val-Asp) [28]. The alkyl tails share similar functionality to amelogenin's $\mathrm{N}$-terminals, controlling the aggregation and assembly of oligopeptide molecules. In an aqueous environment, the hydrophobic alkyl tails pack together toward the core whereas oligopeptide segments are drawn to the periphery. This phenomenon causes the synthesized amphiphilic peptide to spontaneously self-assemble into a nano-fibrous structure. Amino acid sequences of the oligopeptide interact with calcium ions to form crystal nucleators which initiates crystal formation. Under the guidance of the self-assembled peptide, the c-axis of the newly formed crystals aligns with the long axis of the fibrous structure.

There are other types of self-assembled peptides, such as oligomeric $\beta$-sheet-forming peptides (like P11-4). Mediated by $\mathrm{pH}$-control and salt screening electrostatic repulsion between oligomeric peptides, oligomeric $\beta$-sheet-forming peptide undergoes spontaneous hierarchical self-assembly into a fibrillar scaffold [63-65]. P11-4 is a rationally designed, $\beta$-sheet-forming, self-assembling peptide comprised of 11 amino acids. In the presence of cations and $\mathrm{pH}<7.4, \mathrm{P} 11-4$ self-assembles into a hierarchical three-dimensional fibrillar scaffold with negatively charged domains [63]. Self-assembled and negatively charged, P11-4 captures $\mathrm{Ca}^{2+}$ ions and forms crystal nucleators while the template simultaneously controls crystal growth and orientation. Tangentially arranged needle-shaped HA crystals are formed $[64,65]$.

Self-assembled peptides are less costly to produce and more stable than native proteins, but their assembly requires triggering by particular conditions, such as specific mineral content and $\mathrm{pH}$ of an individual's saliva [63-65]. Hence, the use of self-assembled peptides is not applicable for patients with certain oral diseases, such as xerostomia. Regardless, more investigations are required to determine the efficacy of self-assembled peptides and to identify their long-term effect.

\subsubsection{Dendrimers and Their Analog-Mediated Mineralization}

Dendrimers are well-defined and structurally controllable amphiphilic polymers. They are also labelled as artificial proteins due to their similarity in topology and dimension [66]. Dendrimers are readily modifiable to different functional groups, such as aminecapped $\left(-\mathrm{NH}_{2}\right)$, carboxylic acid-capped $(-\mathrm{COOH})$ and acetamide-capped $\left(-\mathrm{NHC}(\mathrm{O}) \mathrm{CH}_{3}\right)$ surfaces [67-69].

Polyamidoamine dendrimer (PAMAM) is a highly-branched polymer characterized by the presence of internal cavities, several reactive end groups and a well-defined size and shape [29]. As a biomimetic macromolecule, PAMAM shares similar properties with 
amelogenin; therefore, it is similarly used as an organic template to regulate the crystallization process. PAMAM's properties as an organic template are based upon its functional terminals which electrostatically bind to oppositely charged arrays in developing enamel crystals along the c-axis [29].

PAMAM can be peripherally modified with different functional groups, such as phenyl, naphthyl, pyrenyl and dansyl [67,69], however, the physical binding strength of PAMAM and its analogs are considered weak. Besides, the results from an in vitro PAMAM study demonstrated that its ability to control crystal growth reduced drastically with time [70].

To strengthen its binding affinity to enamel crystals, PAMAM-based dendrimers can be modified to other functional groups. For example, binding to alendronate (ALN) improves PAMAM-COOH's affinity to the enamel crystal surface. ALN-modified PAMAM-COOH shows a highly organized orientation aligning along the crystal c-axis, which triggers crystal nucleation by its peripherical carboxyl domains to attract calcium ions, and induces the formation of enamel-like crystals parallelly growing along the c-axis of the original enamel prisms [70].

A separate research group modified PAMAM with a focal aliphatic chain and peripherical L-aspartic acids [71]. The hydrophilic branches and carboxyl groups located in the outer layer of SA-PAMAM-ASP improved its adhesive properties compared to PAMAM dendrimers. At pH 7.4 and $37^{\circ} \mathrm{C}$, SA-PAMAM-ASP nanospheres aggregate and assemble into short linear chains that are approximately $300 \mathrm{~nm}-1.5 \mathrm{~mm}$ in length, morphologically resembling self-assembled amelogenin during amelogenesis. SA-PAMAM-ASP assemblies during the crystalline process selectively adsorb onto a/b crystallographic planes, resulting in the formation of oriented crystal filaments [36].

\subsubsection{Surfactants Mediated Mineralization}

Surfactants consist of a combination of hydrophilic and lipophilic components. Due to their amphiphilic properties, surfactants display a specific self-assembly behavior in emulsions. Surfactants oppositely align their polar head groups away from non-polar organic solvents in order to form reversed micelles [72]. The micellar aggregates have a preferred assembled size and shape (e.g., spherical, cylindrical and dislike micelles/vesicles/bilayers). The molecular geometry of surfactant molecules is dependent upon packing parameters, such as the ratio of the aqueous to organic phase in the reverse micelle, and $\mathrm{pH}$ values [73]. In the surfactant-mediated mineralization system, crystal nucleation and growth take place within constraints of the surfactant micelles. Assembled micellar aggregates are used as templates to control crystal morphology and size, and induce oriented attachment in order to form specific crystal structures.

Surfactants are classified based on their charge either as ionic and nonionic [74]. Ionic and nonionic surfactants display distinct spatial rearrangements of micelles and $\mathrm{Ca}^{2+}$ binding capacities due to differences in composition of their hydrophilic head. Ionic surfactants, the majority of which encompass cationic surfactants, electrostatically bind to $\mathrm{Ca}^{2+}$. Binding of $\mathrm{Ca}^{2+}$ to micellar/solution interfaces (referred to as the Stern layer) inhibits electrostatic repulsion between surfactant head groups, thereby permitting micellar rearrangement.

\section{Nonionic Surfactant}

Nonionic surfactants, such as NP5 (poly(oxyethylene) 5 nonylphenol ether) and NP12 (poly(oxyethylene)12 nonylphenol ether), interact with $\mathrm{Ca}^{2+}$ through hydrophilic functional groups (e.g., $\mathrm{C}=\mathrm{O}$ and $-\mathrm{O}-)^{62}$. Nonionic surfactants have weak $\mathrm{Ca}^{2+}$ interactions given their absence of charge, and as a consequence, the system forms weak and randomly organized "mineral-organic" interfaces. One study showed that a nonionic surfactant can regulate the crystallization process, but only under extreme conditions [75]. Thus, there is a limited effect of nonionic surfactants on inducing oriented attachment of crystals. 


\section{Ionic Surfactant}

Ionic surfactants are composed of charged headgroups and counterions (e.g., sodium, potassium or ammonium ions). Ionic surfactants in a metastable mineralization solution self-assemble into an organized structure, driven by non-covalent interactions, such as hydrogen bonding, hydrophobic effects, electrostatic interaction and van der Waals forces. Ionic surfactants form complexes by preferentially binding $\mathrm{Ca}^{2+}$, resulting in slow ion aggregation and a decrease in free energy of solution [31]. After binding to $\mathrm{Ca}^{2+}$ ions, self-assembled surfactants are the template that initiates crystal nucleation, regulates crystal growth, forms oriented attachment and generates an organized crystal structure.

Bis (2-ethylhexyl) sulfosuccinate sodium salt (AOT) is the most common surfactant, containing a hydrophilic end group $-\mathrm{SO}_{3}{ }^{-} \mathrm{Na}^{+}$and two long-chain alkyl hydrophobic terminals. AOT molecules in an electrolyte solution self-assemble into a plate or bilayer structure. Through electrostatic adsorption onto lateral crystal surfaces with exposed $\mathrm{Ca}^{2+}$, AOT mediates crystal growth along the long-axis, blocking active growth sites and gradually decreasing the rate of crystallization [31].

An AOT/water/isooctane phase diagram was established to tailor structures of selfassembled AOT aggregates. Under this diagram, varying molar ratios of water to AOT and the addition of hydrophobic molecules increase the effective volume of the AOT, thereby altering its critical packing parameter [76]. There is evidence showing that a relatively high molar ratio of AOT concerning water leads to stronger interactions between $\mathrm{Ca}^{2+}$ and the AOT head group. The change in viscosity of the solution affects crystal type, growth kinetics and organization [31]. Under the AOT/water/isooctane diagram, calcium and phosphate ions added separately to an AOT isooctane solution form AOT-stabilized reverse micelles or microemulsions. $\mathrm{Ca}^{2+}$ ions electrostatically bind to sulfonate heads of AOT and follow geometry dictated by the association of AOT molecule. AOT molecules self-assemble into lamellar structures at the isooctane/water interface via interaction of the hydrophilic end with water and their long and ramified hydrophobic end join up in isooctane [31]. Mixing the two separate solutions results in high viscosity of a calcium phosphate solution, similar to the viscous nature of the amelogenin gel matrix in developing enamel. Crystal nucleation and early growth are conducted within mini-reaction vessels resulting in the formation of entangled rod-like surfactant micelles. The growth of the mineral results in rearrangement of rod-like micelles and induces a strong interaction with the crystal faces. The interaction accommodates an increase in crystal length and diameter to direct mineral growth and the formation of elongated hydroxyapatite.

Other ionic surfactants such as potassium polyoxyethylene laurylether phosphate (MAEPK), sodium dodecyl sulfate (SDS) and disodium oleoamido PEG-2 sulfosuccinate (SPEG) also synthesize enamel-like crystals [13,77]. SPEG is a polymer-based, two-headed amphiphilic molecule that can form prolate-shaped micelles. Its two proximally located headgroups, $\mathrm{COO}-$ and $\mathrm{SO} 3-$, characterize its higher electrostatic surface potential and inhibitory efficiency compared to one-headed anionic surfactants. A comparison on the regulation of the crystallization process amongst different surfactants, to our knowledge, has not been investigated.

\subsubsection{EDTA Mediated Mineralization}

EDTA is a chelating agent that sequesters $\mathrm{Ca}^{2+}$ to form EDTA-Ca complexes. EDTA diminishes $\mathrm{Ca}^{2+}$ reactivity, slows the rate of crystal nucleation and mediates crystal growth The strength of chelation is dependent upon $\mathrm{pH}$; EDTA is a stronger chelator of $\mathrm{Ca}^{2+}$ at higher $\mathrm{pH}$ [78].

$\mathrm{Ca}^{2+}$ ions interacting with $\mathrm{PO}_{4}{ }^{3-}$ ions in a metastable mineralization solution decrease surface energy and increase stability in solution by forming ACP nanospheres. Different diffusion coefficients between ACP nanospheres and solution during the crystalline process cause a net flux of ACP from the ACP sphere from a higher diffusion coefficient to a lower diffusion coefficient. To balance the flux, a flux of vacancies in the opposite direction arises from solution into the ACP sphere, leading to the outwards infusion of ACP from the 
ACP sphere and giving rise to the formation of a core-shell or shell structure without ACP inclusions, a phenomenon called the Kirkendall effect. The continuous outward diffusion of ACP nanospheres promotes the subsequent growth of HA. Due to the large surface area of the shell structure, small crystals within the structure are energetically unfavorable and easily dissolve and diffuse into solution. The crystals are redeposited onto HA, promoting their growth [79]. $\mathrm{Ca}^{2+}$ gradually dissociates from the EDTA-Ca complexes and displays preferential binding to the crystal's polar (001) direction [71]. Diffusion-limited growth leads to the formation of single nanorods from each nucleate and the formation of spear-like crystals with one sharp end [78]. Van der Waals attraction along the crystal long axis causes HA nanorods to aggregate and align in parallel leading to bundle formation. As a result of the Ostwald ripening process, neighboring crystal bundles fuse together, lowering surface energy and generating the construction of a shuttle-like structure.

For non-protein based organic matrix-mediated biomineralization systems, there are no complications in protein extraction, purity and storage, but the remineralization process is time-consuming; thus, its practical use remains far from clinical application. Dendrimers are also far from clinical translation. Investigations have been limited to in vivo studies and animal models and similar to self-assembled proteins, the effectiveness of a non-protein mediated mineralization system is also highly influenced by environmental conditions, such as mineral content and $\mathrm{pH}$. Likewise, the system relies on the quality of saliva, which is not necessarily suitable for certain patients suffering from dry mouth.

\section{Regeneration of Enamel Microstructure Induced by the Template of the Cation Membrane System}

$\mathrm{Ca}^{2+}$ and $\mathrm{PO}_{4}{ }^{3-}$ ions are transported from the ameloblast layer into the gel-like enamel extracellular matrix during enamel formation. With conditions conducive to mineral growth and extension, ameloblasts draw back from the mineralizing area resulting in one-directional $\mathrm{Ca}^{2+}$ and $\mathrm{PO}_{4}{ }^{3-}$ supply. Once full extension of the enamel crystals terminates, ameloblasts transform into shortened heights and lose their Tomes' process. Iijima et al. [41,80,81] developed a cation selective membrane system to mimic the growth environment during amelogenesis.

\subsection{One-Directional $\mathrm{Ca}^{2+}$ Supply}

This model highlights the contribution of a one-directional $\mathrm{Ca}^{2+}$ ion supply which promotes the lengthwise and oriented growth of enamel crystals [80,81]. In such a device, a cation-selective membrane separates a $\mathrm{Ca}^{2+}$ reactant solution from a $\mathrm{PO}_{4}$ reactant. The membrane is composed of a styrene-butadiene copolymer containing $-\mathrm{SO}_{3}$ - functional groups and controls the direction of $\mathrm{Ca}^{2+}$ transport into the $\mathrm{PO}_{4}$ compartment. Compared with crystals formed in solution, crystals grown on the cation membrane are longer in the c-axis direction and display a parallel and organized orientation. One-directional ionic supply through the membrane plays a key role in c-axial lengthwise growth and crystal orientation.

\subsection{Hydrogel Matrix}

Crystal growth of tooth enamel occurs within the enamel matrix composed of enamel proteins. High viscosity and gel-like properties characterize the composition of the matrix in the secretory stage. A polyacrylamide gel is applied to the $\mathrm{PO}_{4}$ side of a cationic selective membrane. Compared to the growth of broad flake-like crystals in a gel-free membrane, narrow elongated plate-like crystals are synthesized using a 5\% gel-coated membrane. These crystals have a greater relative length (length to width ratio) than in a gel-free membrane. In the gel-coated cation selective membrane system, $\mathrm{Ca}^{2+}$ and $\mathrm{PO}_{4}$ ions diffuse into the body of the gel in mutually opposite directions, causing a steady unidirectional diffusion of these ions [80]. This set up enhances the steadiness of ionic flow in the middle of the gel layer and promotes crystal orientation and lengthwise growth. 
One disadvantage of the system is that disruptive convection currents can at times have a measurable destabilizing effect on growth in regions near the surfaces.

\section{3. $\mathrm{Ca}^{2+}$ and $\mathrm{PO}_{4}{ }^{3-}$ Ionic Inflow, and $\mathrm{pH}$ Value}

During enamel crystal formation, $\mathrm{Ca}^{2+}$ and $\mathrm{PO}_{4}{ }^{3-}$ ions are transported into the enamel matrix, accompanied by changes in the $\mathrm{Ca} / \mathrm{PO}_{4}$ ratio within the calcified enamel matrix. The formation of enamel crystallites is also influenced by ionic transport. Crystals growing in a cation selective membrane system have an increased length to width (L/W) ratio, decreased width to thickness (W/T) ratio and increased $\mathrm{Ca}^{2+}$ and $\mathrm{PO}_{4}$ concentrations [82].

Crystal growth using membranes with lower $\mathrm{pH}$ values and $\mathrm{PO}_{4}$ concentrations show preferential growth in the c-axis direction. $\mathrm{H}^{+}$ions are effective in promoting lengthwise crystal growth.

\section{Electrolytic Deposition (ELD) Mineralization System}

The $\mathrm{pH}$ of the extracellular matrix is maintained within a dynamic range during amelogenesis [6]. The $\mathrm{pH}$ is neutral (7.2) during the secretory stage. Crystal nucleation occurs during the early stages of crystal maturation, forming hydrogen byproducts which lower the $\mathrm{pH}$ [83]. To maintain $\mathrm{pH}$ homeostasis and prevent disruptions in crystal growth, ameloblasts regulate the enamel extracellular $\mathrm{pH}$ through an acid-base transport mechanism. During the latter stages of maturation, enamel extracellular $\mathrm{pH}$ values rise above neutral [83].

An electrolytic system using continuous electrolysis reactions was introduced for mimicking the buffering system of ameloblasts [84]. This system utilizes an electrical current with the following electrochemical reactions occurring at the cathode.

$$
\begin{gathered}
2 \mathrm{H}^{+}+2 \mathrm{e}^{-}=\mathrm{H}_{2} \\
1 / 2 \mathrm{O}_{2}+\mathrm{H}_{2} \mathrm{O}+2 \mathrm{e}^{-}=2 \mathrm{OH}^{-}
\end{gathered}
$$

The generated hydroxyl ions neutralize excess hydrogen arising from crystal nucleation. They also increase local $\mathrm{pH}$, which aids in promoting the growth of the hydroxyapatite crystallite. Self-assembly of amelogenin is $\mathrm{pH}$-dependent. The ELD system also regulates the assembly of amelogenin. The supersaturation degree of calcium phosphate solution rises in response to the increase in $\mathrm{pH}$ in order to initiate crystal nucleation.

Fan et al. fabricated an enamel-like structure composite using electrolytic deposition [84]. At pH 4.8, positively charged amelogenin is driven towards the cathode. Electrochemical reactions at the cathode increase the $\mathrm{pH}$ from 4.8 to 8 and solution $\mathrm{pH}$ from 4.8 to 5.7 during electrolytic deposition. Amelogenin aggregates, in response to higher $\mathrm{pH}$, self-assemble into parallel-oriented nanochain structures. This coincides with the formation of enamel-like structures on the surface of the cathodal electrode, which are generated from the calcium phosphate solution. There are some reports describing the formation of enamel-like structures directly induced by electrolytic deposition [85-87].

Although studies have demonstrated the safety of an external electric field and its benefits on accelerating mineral deposition, its repair efficiency remains low. The mineralization process occurs over several hours and results in the low production of a thin mineral. The feasibility of using the electrolytic deposition approach at the level of the dental clinic remains uncertain.

\section{The Outlook}

We reviewed the process of amelogenesis and summarized various biomimetic strategies for the regeneration of enamel-like structures. Reconstructing the hierarchical structure of enamel is an efficacious method to treat dental hard tissue lesions and resolve treatment limitations caused by the mismatch of artificial materials and native dental tissue. Studies have investigated the mechanisms of amelogenesis, utilizing insights gained from the regulation of the crystallization process as a model to reconstruct the distinct structure of 
native enamel. Significant achievements utilizing biomimetic approaches in tooth repair have been achieved; however, current biomimetic mineralization approaches can only reproduce repaired layers at laboratory scale. Accurate crystallographic alignment between crystalline blocks over large dimensions is difficult to achieve at present [85-88]. A detailed mechanism of oriented attachment has not been fully elucidated, such as the function and evolution of organic matrices during crystal formation. It is important to develop cost-effective, industrial scale synthesis for biomimetic strategies to translate into the clinical setting. Synthesis has to produce a repaired layer with a hierarchically organized structure and high strength; repair efficiencies of current biomimetic approaches need to be improved. In summary, while the studies outlined in this overview are promising, how these biomimetic approaches translate into the dental clinic to repair enamel structure need to be highlighted in future studies.

Author Contributions: Y.Y.Z., H.M.W. and Q.L.L. contributed to the conception and design of the study and drafted the manuscript. All authors contributed towards critically revising the manuscript, giving final approval and agreeing to be accountable for all aspects of the work ensuring integrity and accuracy. All authors have read and agreed to the published version of the manuscript.

Funding: This research was funded by the NSFC/RGC Joint Research Scheme sponsored by the Research Grants Council of the Hong Kong Special Administrative Region, China, and the National Natural Science Foundation of China, Grant No. N-HKU706/20.

Data Availability Statement: All of the data reported in this work as available upon request.

Acknowledgments: The work described in this paper was fully supported by a grant from the NSFC/RGC Joint Research Scheme sponsored by the Research Grants Council of the Hong Kong Special Administrative Region, China, and the National Natural Science Foundation of China (Project No. N-HKU706/20).

Conflicts of Interest: The authors declare no competing financial interest.

\section{References}

1. Solaymani, S.; Ghoranneviss, M.; Elahi, S.M.; Shafiekhani, A.; Kulesza, S.; Ţălu, Ş.; Bramowicz, M.; Hantehzadeh, M.; Nezafat, N.B. The relation between structural, rugometric and fractal characteristics of hard dental tissues at micro and nano levels. Microsc. Res. Tech. 2019, 82, 421-428. [CrossRef] [PubMed]

2. De Dios Teruel, J.; Alcolea, A.; Hernández, A.; Ruiz, A.J.O. Comparison of chemical composition of enamel and dentine in human, bovine, porcine and ovine teeth. Arch. Oral Biol. 2015, 60, 768-775. [CrossRef] [PubMed]

3. Yamamoto, T.; Hasegawa, T.; Yamamoto, T.; Hongo, H.; Amizuka, N. Histology of human cementum: Its structure, function, and development. Jpn. Dent. Sci. Rev. 2016, 52, 63-74. [CrossRef] [PubMed]

4. Lacruz, R.S.; Habelitz, S.; Wright, J.T.; Paine, M.L. Dental enamel formation and implications for oral health and disease. Physiol. Rev. 2017, 97, 939-993. [CrossRef]

5. Kreulen, C.M.; Van't Spijker, A.; Rodriguez, J.M.; Bronkhorst, E.M.; Creugers, N.H.J.; Bartlett, D.W. Systematic review of the prevalence of tooth wear in children and adolescents. Caries Res. 2010, 44, 151-159. [CrossRef]

6. Moradian-Oldak, J. Protein-mediated enamel mineralization. Front. Biosci. 2012, 17, 1996. [CrossRef]

7. Featherstone, J.D.B. Remineralization, the natural caries repair process-The need for new approaches. Adv. Dent. Res. 2009, 21, 4-7. [CrossRef]

8. Pitts, N.B.; Wefel, J.S. Remineralization/desensitization: What is known? What is the future? Adv. Dent. Res. 2009, 21, 83-86. [CrossRef]

9. Chen, H.F.T.Z.; Tang, Z.; Liu, J.; Sun, K.; Chang, S.R.; Peters, M.C.; Mansfield, J.F.; Czajka-Jakubowska, A.; Clarkson, B.H. Acellular synthesis of a human enamel-like microstructure. Adv. Mater. 2006, 18, 1846-1851. [CrossRef]

10. Zou, Z.; Liu, X.; Chen, L.; Lin, K.; Chang, J. Dental enamel-like hydroxyapatite transformed directly from monetite. J. Mater. Chem. 2012, 22, 22637-22641. [CrossRef]

11. Yamagishi, K.; Onuma, K.; Suzuki, T.; Okada, F.; Tagami, J.; Otsuki, M.; Senawangse, P. A Synthetic enamel for rapid tooth repair. Nature 2005, 433, 819. [CrossRef] [PubMed]

12. Zhan, J.; Tseng, Y.H.; Chan, J.C.; Mou, C.Y. Biomimetic formation of hydroxyapatite nanorods by a single-crystal-to-single-crystal transformation. Adv. Funct. Mater. 2005, 15, 2005-2010. [CrossRef]

13. Handa, T.; Anada, T.; Honda, Y.; Yamazaki, H.; Kobayashi, K.; Kanda, N.; Kamakura, S.; Echigo, S.; Suzuki, O. The effect of an octacalcium phosphate co-precipitated gelatin composite on the repair of critical-sized rat calvarial defects. Acta Biomater. 2012, 8, 1190-1200. [CrossRef] 
14. Ethirajan, A.; Ziener, U.; Chuvilin, A.; Kaiser, U.; Cölfen, H.; Landfester, K. Biomimetic hydroxyapatite crystallization in gelatin nanoparticles synthesized using a miniemulsion process. Adv. Funct. Mater. 2008, 18, 2221-2227. [CrossRef]

15. Jiao, M.J.; Wang, X.X. Electrolytic deposition of magnesium-substituted hydroxyapatite crystals on titanium substrate. Mater Lett. 2009, 63, 2286-2289. [CrossRef]

16. Lei, C.; Liao, Y.; Feng, Z. Kinetic model for hydroxyapatite precipitation on human enamel surface by electrolytic deposition. Biomed. Mater. 2009, 4, 035010. [CrossRef]

17. Moradian-Oldak, J. The regeneration of tooth enamel. Dimens. Dent. Hyg. 2009, 7, 12. [PubMed]

18. Zafar, M.S.; Amin, F.; Fareed, M.A.; Ghabbani, H.; Riaz, S.; Khurshid, Z.; Kumar, N. Biomimetic aspects of restorative dentistry biomaterials. Biomimetics 2020, 5, 34. [CrossRef]

19. Qasim, S.S.B.; Zafar, M.S.; Niazi, F.H.; Alshahwan, M.; Omar, H.; Daood, U. Functionally graded biomimetic biomaterials in dentistry: An evidence-based update. J. Biomater. Sci. Polym. Ed. 2020, 31, 1144-1162. [CrossRef] [PubMed]

20. Gandolfi, M.G.; Taddei, P.; Siboni, F.; Modena, E.; Ginebra, M.P.; Prati, C. Fluoride-containing nanoporous calcium-silicate MTA cements for endodontics and oral surgery: Early fluorapatite formation in a phosphate-containing solution. Int. Endod. J. 2011, 44, 938-949. [CrossRef]

21. Bossù, M.; Saccucci, M.; Salucci, A.; Di Giorgio, G.; Bruni, E.; Uccelletti, D.; Sarto, M.S.; Familiari, G.; Relucenti, M.; Polimeni, A. Enamel remineralization and repair results of Biomimetic Hydroxyapatite toothpaste on deciduous teeth: An effective option to fluoride toothpaste. J. Nanobiotechnol. 2019, 17, 17. [CrossRef] [PubMed]

22. Wang, S.; Zhang, L.; Chen, W.; Jin, H.; Zhang, Y.; Wu, L.; Shao, H.; Fang, Z.; He, X.; Zheng, S.; et al. Rapid regeneration of enamel-like-oriented inorganic crystals by using rotary evaporation. Mater. Sci. Eng. 2020, 115, 111141. [CrossRef] [PubMed]

23. Fan, Y.; Sun, Z.; Wang, R.; Abbott, C.; Moradian-Oldak, J. Enamel inspired nanocomposite fabrication through amelogenin su pramolecular assembly. Biomaterials 2007, 28, 3034-3304. [CrossRef]

24. Kwak, S.Y.; Litman, A.; Margolis, H.C.; Yamakoshi, Y.; Simmer, J.P. Biomimetic enamel regeneration mediated by leucine-rich amelogenin peptide. J. Dent. Res. 2017, 96, 524-530. [CrossRef] [PubMed]

25. Carneiro, K.M.; Zhai, H.; Zhu, L.; Horst, J.A.; Sitlin, M.; Nguyen, M.; Wagner, M.; Simpliciano, C.; Milder, M.; Chen, C.L.; et al. Amyloid-like ribbons of amelogenins in enamel mineralization. Sci. Rep. 2016, 6, 23105. [CrossRef]

26. Shafiei, F.; Hossein, B.G.; Farajollahi, M.M.; Fathollah, M.; Marjan, B.; Tahereh, J.K. Leucine-rich amelogenin peptide (LRAP) as a surface primer for biomimetic remineralization of superficial enamel defects: An in vitro study. Scanning 2015, 37, 179-185. [CrossRef]

27. Le Norcy, E.; Kwak, S.Y.; Wiedemann-Bidlack, F.B.; Beniash, E.; Yamakoshi, Y.; Simmer, J.P.; Margolis, H.C. Leucine-rich ame logenin peptides regulate mineralization in vitro. J. Dent. Res. 2011, 90, 1091-1097. [CrossRef]

28. Li, Q.L.; Ning, T.Y.; Cao, Y.; Zhang, W.B.; Mei, M.L.; Chu, C.H. A novel self-assembled oligopeptide amphiphile for biomimetic mineralization of enamel. BMC Biotechnol. 2014, 14, 32. [CrossRef]

29. Philip, N. State of the art enamel remineralization systems: The next frontier in caries management. Caries Res. 2019, 53, 284-295. [CrossRef]

30. Zhou, L.; Wong, H.M.; Zhang, Y.Y.; Li, Q.L. Constructing an antibiofouling and mineralizing bioactive tooth surface to protect against decay and promote self-healing. ACS Appl. Mater. Interfaces 2019, 12, 3021-3031. [CrossRef]

31. Zhang, F.; Zhou, Z.H.; Yang, S.P.; Mao, L.H.; Chen, H.M.; Yu, X.B. Hydrothermal synthesis of hydroxyapatite nanorods in the presence of anionic starburst dendrimer. Mater. Lett. 2005, 59, 1422-1425. [CrossRef]

32. Fowler, C.E.; Li, M.; Mann, S.; Margolis, H.C. Influence of surfactant assembly on the formation of calcium phosphate materials-A model for dental enamel formation. J. Mater. Chem. 2005, 15, 3317-3325. [CrossRef]

33. Pandya, M.; Diekwisch, T.G.H. Enamel biomimetics-fiction or future of dentistry. Int. J. Oral Sci. 2019, 11, 8. [CrossRef] [PubMed]

34. Beniash, E.; Stifler, C.A.; Sun, C.Y.; Jung, G.S.; Qin, Z.; Buehler, M.J.; Gilbert, P.U.P.A. The hidden structure of human enamel. Nat. Commun. 2019, 10, 4383. [CrossRef]

35. Rivera, C.; Arola, D.; Ossa, A. Indentation damage and crack repair in human enamel. J. Mech. Behav. Biomed. Mater. 2013, 21, 178-184. [CrossRef] [PubMed]

36. Lokappa, S.B.; Chandrababu, K.B.; Moradian-Oldak, J. Tooth enamel protein amelogenin binds to ameloblast cell membranemimicking vesicles via its N-terminus. Biochem. Biophys. Res. Commun. 2015, 464, 956-961. [CrossRef]

37. Mukherjee, K.; Ruan, Q.; Nutt, S.; Tao, J.; De Yoreo, J.J.; Moradian-Oldak, J. Peptide-based bioinspired approach to regrowing multilayered aprismatic enamel. ACS Omega 2018, 3, 2546-2557. [CrossRef]

38. Beniash, E.; Simmer, J.P.; Margolis, H.C. Structural changes in amelogenin upon self-assembly and mineral interactions. J. Dent. Res. 2012, 91, 967-972. [CrossRef]

39. Bromley, K.M.; Kiss, A.S.; Lokappa, S.B.; Lakshminarayanan, R.; Fan, D.; Ndao, M.; Evans, J.S.; Moradian-Oldak, J. Dissecting amelogenin protein nanospheres characterization of metastable oligomers. J. Biol. Chem. 2011, 286, 34643-34653. [CrossRef]

40. Fincham, A.G.; Moradian-Oldak, J.; Simmer, J.P. The structural biology of the developing dental enamel matrix. J. Struct. Biol. 1999, 126, 270-299. [CrossRef]

41. Iijima, M.; Moradian-Oldak, J. Interactions of amelogenins with octacalcium phosphate crystal faces are dose dependent. Calcif. Tissue Int. 2004, 74, 522-531. [CrossRef]

42. Iijima, M.; Moriwaki, Y.; Takagi, T.; Moradian-Oldak, J. Effects of bovine amelogenins on the crystal morphology of octacalcium phosphate in a model system of tooth enamel formation. J. Cryst. Growth 2001, 222, 615-626. [CrossRef] 
43. Beniash, E.; Simmer, J.P.; Margolis, H.C. The effect of recombinant mouse amelogenins on the formation and organization of hydroxyapatite crystals in vitro. J. Struct. Biol. 2005, 149, 182-190. [CrossRef] [PubMed]

44. Fukumoto, S.; Kiba, T.; Hall, B.; Iehara, N.; Nakamura, T.; Longenecker, G.; Krebsbach, P.H.; Nanci, A.; Kulkarni, A.B.; Yamada, Y. Ameloblastin is a cell adhesion molecule required for maintaining the differentiation state of ameloblasts. J. Cell Biol. 2004, 167, 973-983. [CrossRef] [PubMed]

45. Fan, D.; Du, C.; Sun, Z.; Lakshminarayanan, R.; Moradian-Oldak, J. In vitro study on the interaction between the $32 \mathrm{kDa}$ enamelin and amelogenin. J. Struct. Biol. 2009, 166, 88-94. [CrossRef] [PubMed]

46. Deutsch, D.; Leiser, Y.; Shay, B.; Fermon, E.; Taylor, A.; Rosenfeld, E.; Dafni, L.; Charuvi, K.; Cohen, Y.; Haze, A.; et al. The human tuftelin gene and the expression of tuftelin in mineralizing and nonmineralizing tissues. Connect. Tissue Res. 2002, 43, $425-434$. [CrossRef]

47. Jain, P.S.; Damle, S.G.; Dedhia, S.P.; Jetpurwala, A.M.; Gupte, T.S. Evaluation of the association between tuftelin gene polymer phism, Streptococcus mutans, and dental caries susceptibility. J. Indian Soc. Pedod. Prev. Dent. 2020, 38, 381-386.

48. Ruan, Q.; Moradian-Oldak, J. Amelogenin and enamel biomimetics. J. Mater. Chem. B 2015, 3, 3112-3129. [CrossRef]

49. Smith, C.E.; Richardson, A.S.; Hu, Y.; Bartlett, J.D.; Hu, J.C.; Simmer, J.P. Effect of Kallikrein 4 Loss on Enamel Mineralization comparison with mice lacking matrix metalloproteinase 20. J. Biol. Chem. 2011, 286, 18149-18160. [CrossRef]

50. Yang, X.; Sun, Z.; Ma, R.; Fan, D.; Moradian-Oldak, J. Amelogenin "nanorods" formation during proteolysis by Mmp-20. J. Struct. Biol. 2011, 176, 220-228. [CrossRef]

51. Kwak, S.Y.; Wiedemann-Bidlack, F.B.; Beniash, E.; Yamakoshi, Y.; Simmer, J.P.; Litman, A.; Margolis, H.C. Role of 20-kDa Amelogenin (P148) Phosphorylation in Calcium Phosphate Formation in vitro. J. Biol. Chem. 2009, 284, 18972-18979. [CrossRef]

52. Ryu, O.; Hu, J.C.; Yamakoshi, Y.; Villemain, J.L.; Cao, X.; Zhang, C.; Bartlett, J.D.; Simmer, J.P. Porcine kallikrein-4 activation, glycosyl ation, activity, and expression in prokaryotic and eukaryotic hosts. Eur. J. Oral Sci. 2002, 110, 358-365. [CrossRef]

53. Yuwono, V.M.; Burrows, N.D.; Soltis, J.A.; Penn, R.L. Oriented aggregation: Formation and transformation of mesocrystal inter mediates revealed. J. Am. Chem. Soc. 2010, 132, 2163-2165. [CrossRef] [PubMed]

54. Penn, R.L.; Soltis, J.A. Characterizing crystal growth by oriented aggregation. CrystEngComm 2014, 16, 1409-1418. [CrossRef]

55. Al-Ghoul, M.; Issa, R.; Hmadeh, M. Synthesis, size and structural evolution of metal-organic framework-199 via a reaction-dif fusion process at room temperature. CrystEngComm 2017, 19, 608-612. [CrossRef]

56. Schliehe, C.; Juarez, B.H.; Pelletier, M.; Jander, S.; Greshnykh, D.; Nagel, M.; Meyer, A.; Foerster, S.; Kornowski, A.; Klinke, C.; et al. Ultrathin PbS sheets by two-dimensional oriented attachment. Science 2010, 329, 550-553. [CrossRef] [PubMed]

57. Cölfen, H.; Mann, S. Higher-order organization by mesoscale self-assembly and transformation of hybrid nanostructures. Angew. Chem. Int. Ed. 2003, 42, 2350-2365. [CrossRef]

58. Mann, S.; Archibald, D.D.; Didymus, J.M.; Douglas, T.; Heywood, B.R.; Meldrum, F.C.; Reeves, N.J. Crystallization at inorganicorganic interfaces: Biominerals and biomimetic synthesis. Science 1993, 261, 1286-1292. [CrossRef]

59. Iijima, M. Modification of octacalcium phosphate growth by enamel proteins, fluoride, and substrate materials and influence of morphology on the performance of octacalcium phosphate biomaterials. In Octacalcium Phosphate Biomaterials; Woodhead Publishing: Sawston, UK, 2020; pp. 309-347.

60. Han, T.; Wang, M.; Cao, C.; Chen, H.; Zhang, G.; Wang, L.; Wang, J. Fluoride or/and aluminum induced toxicity in guinea pig teeth with the low expression of dentine phosphoprotein. J. Biochem. Mol. Toxicol. 2017, 31, e21912. [CrossRef]

61. Hsu, C.C.; Chung, H.Y.; Yang, J.M.; Shi, W.; Wu, B. Influence of 8DSS peptide on nano-mechanical behavior of human enamel. J. Dent. Res. 2011, 90, 88-92. [CrossRef]

62. Semino, C.E. Self-assembling peptides: From bio-inspired materials to bone regeneration. J. Dent. Res. 2008, 87, 606-616. [CrossRef] [PubMed]

63. Brunton, P.A.; Davies, R.P.W.; Burke, J.L.; Smith, A.; Aggeli, A.; Brookes, S.J.; Kirkham, J. Treatment of early caries lesions using biomimetic self-assembling peptides-A clinical safety trial. Br. Dent. J. 2013, 215, E6. [CrossRef]

64. Kind, L.; Stevanovic, S.; Wuttig, S.; Wimberger, S.; Hofer, J.; Müller, B.; Pieles, U. Biomimetic remineralization of carious lesions by self-assembling peptide. J. Dent. Res. 2017, 96, 790-797. [CrossRef]

65. Kirkham, J.; Firth, A.; Vernals, D.; Boden, N.; Robinson, C.; Shore, R.C.; Brookes, S.J.; Aggeli, A. Self-assembling peptide scaffolds. promote enamel remineralization. J. Dent. Res. 2007, 86, 426-430. [CrossRef] [PubMed]

66. Noriega-Luna, B.; Godínez, L.A.; Rodríguez, F.J.; Rodríguez, A.; Zaldívar-Lelo de Larrea, G.; Sosa-Ferreyra, C.F.; Mercado-Curiel, R.F.; Manríquez, J.; Bustos, E. Applications of dendrimers in drug delivery agents, diagnosis, therapy, and detection. J. Nanomater. 2014, 2014, 507273. [CrossRef]

67. Esfand, R.; Tomalia, D.A. Poly (amidoamine)(PAMAM) dendrimers: From biomimicry to drug delivery and biomedical applications. Drug Discov. Today 2001, 6, 427-436. [CrossRef]

68. Kesharwani, P.; Banerjee, S.; Gupta, U.; Amin, M.C.I.M.; Padhye, S.; Sarkar, F.H.; Iyer, A.K. PAMAM dendrimers as promising nanocarriers for RNAi therapeutics. Mater. Today 2015, 18, 565-572. [CrossRef]

69. Niu, Y.; Qu, R.; Chen, H.; Mu, L.; Liu, X.; Wang, T.; Zhang, Y.; Sun, C. Synthesis of silica gel supported salicylaldehyde modified PAMAM dendrimers for the effective removal of $\mathrm{Hg}$ (II) from aqueous solution. J. Hazard. Mater. 2014, 278, 267-278. [CrossRef] [PubMed]

70. Wu, D.; Yang, J.; Li, J.; Chen, L.; Tang, B.; Chen, X.; Wu, W.; Li, J. Hydroxyapatite-anchored dendrimer for in situ remineralization of human tooth enamel. Biomaterials 2013, 34, 5036-5047. [CrossRef] 
71. Yang, S.; He, H.; Wang, L.; Jia, X.; Feng, H. Oriented crystallization of hydroxyapatite by the biomimetic amelogenin nanospheres from self-assemblies of amphiphilic dendrons. Chem. Commun. 2011, 47, 10100-10102. [CrossRef]

72. Bujan, M.; Sikirić, M.; Filipović-Vinceković, N.; Vdović, N.; Garti, N.; Füredi-Milhofer, H. Effect of anionic surfactants on crystal growth of calcium hydrogen phosphate dihydrate. Langmuir 2001, 17, 6461-6470. [CrossRef]

73. Althues, H.; Kaskel, S. Sulfated zirconia nanoparticles synthesized in reverse microemulsions: Preparation and catalytic properties. Langmuir 2002, 18, 7428-7435. [CrossRef]

74. Qi, L.; Ma, J.; Cheng, H.; Zhao, Z. Microemulsion-mediated synthesis of calcium hydroxyapatite fine powders. J. Mater. Sci. Lett. 1997, 16, 1779-1781. [CrossRef]

75. Ye, F.; Guo, H.; Zhang, H. Biomimetic synthesis of oriented hydroxyapatite mediated by nonionic surfactants. Nanotechnology 2008, 19, 245605. [CrossRef] [PubMed]

76. Vasquez, V.R.; Williams, B.C.; Graeve, O.A. Stability and comparative analysis of AOT/water/isooctane reverse micelle system using dynamic light scattering and molecular dynamics. J. Phys. Chem. B 2011, 115, 2979-2987. [CrossRef]

77. Yang, S.; Chen, J.; Wang, Z.; Zhang, H.; Zhang, Q. Surfactant-assisted synthesis of oriented hydroxyapatite nanoclusters by reflux method. Mater. Lett. 2013, 96, 177-180. [CrossRef]

78. Liu, J.; Li, K.; Wang, H.; Zhu, M.; Xu, H.; Yan, H. Self-assembly of hydroxyapatite nanostructures by microwave irradiation. Nanotechnology 2004, 16, 82. [CrossRef]

79. Ardell, A.J. Non-integer temporal exponents in trans-interface diffusion-controlled coarsening. J. Mater. Sci. 2016, 51, 6133-6148 [CrossRef]

80. Iijima, M.; Moriwaki, Y. Lengthwise and oriented growth of octacalcium phosphate crystal in polyacrylamide gel in a model system of tooth enamel apatite formation. J. Cryst. Growth 1998, 194, 125-132. [CrossRef]

81. Iijima, M.; Moriwaki, Y.; Kuboki, Y. Oriented and lengthwise growth of octacalcium phosphate on collagenous matrix in vitro. Connect. Tissue Res. 1997, 36, 51-61. [CrossRef]

82. Iijima, M.; Kamemizu, H.; Wakamatsu, N.; Goto, T.; Doi, Y.; Moriwaki, Y. Transition of octacalcium phosphate to hydroxyapatite in solution at pH 7.4 and 37 C. J. Cryst. Growth 1997, 181, 70-78. [CrossRef]

83. Lacruz, R.S.; Nanci, A.; Kurtz, I.; Wright, J.T.; Paine, M.L. Regulation of pH during amelogenesis. Calcif. Tissue Int. 2010, 86, 91-103. [CrossRef]

84. Zhitomirsky, I. Cathodic electrodeposition of ceramic and organoceramic materials. Fundamental aspects. Adv. Colloid Interface Sci. 2002, 97, 279-317. [CrossRef]

85. Zhang, Y.Y.; Wong, H.M.; McGrath, C.P.; Li, Q.L. In vitro and in vivo evaluation of electrophoresis-aided casein phosphopeptideamorphous calcium phosphate remineralisation system on $\mathrm{pH}$-cycling and acid-etching demineralised enamel. Sci. Rep. 2018, 8, 8904. [CrossRef] [PubMed]

86. Wu, X.T.; Mei, M.L.; Li, Q.L.; Cao, C.Y.; Chen, J.L.; Xia, R.; Zhang, Z.H.; Chu, C.H. A direct electric field-aided biomimetic mineralization system for inducing the remineralization of dentin collagen matrix. Materials 2015, 8, 7889-7899. [CrossRef] [PubMed]

87. Zhang, Y.Y.; Wong, H.M.; McGrath, C.P.; Li, Q.L. Repair of dentine-related lesions without a drill or injection. RSC Adv. 2019, 9, 15099-15107. [CrossRef]

88. Kim, Y.; Schenk, A.; Ihli, J.; Kulak, A.; Hetherington, N.; Tang, C.; Schmahl, W.; Griesshaber, E.; Hyett, G.; Meldrum, F. A critical analysis of calcium carbonate mesocrystals. Nat. Commun. 2014, 5, 4341. [CrossRef] 